\title{
Relationship of uterine closure to ovarian hormones and endocytosis in the rat
}

\author{
Margaret B. Parr* \\ The Flinders University of South Australia, Unit of Human Morphology, School of Medicine, \\ Bedford Park, South Australia 5042
}

\begin{abstract}
Summary. Ovariectomized rats were treated with various hormonal regimens. The first stage of uterine closure and epithelial cell endocytosis were observed in ovariectomized rats treated with progesterone or progesterone after oestrogen priming but not in hormonally untreated rats or those treated with oestrogen alone. The simultaneous appearance of closure and endocytosis in response to the same physiological conditions is consistent with the proposal that the endocytotic activity in the uterine epithelial cells may remove fluid from the uterine lumen and thus mediate the first stage of uterine closure.
\end{abstract}

\section{Introduction}

Closure of the uterine lumen occurs during early pregnancy just before implantation of the blastocysts in rats and mice. At this time, the microvilli from apposed luminal epithelial cells interdigitate with one another or, where the embryo is present, with those of the trophoblast. This period of development is called the pre-attachment phase (Mayer, Nilsson \& Reinius, 1967), the apposition stage (Enders \& Schlafke, 1969) or the first stage of closure (Finn, 1975), and occurs not only during normal pregnancy but also during delay of implantation and in ovariectomized animals treated with progesterone (Martin, Finn \& Carter, 1970; Hedlund \& Nilsson, 1971).

The physiological cause of uterine closure is not known. Mayer et al. (1967) and Enders \& Nelson (1973) have suggested that resorption of fluid from the uterine lumen by endocytosis may facilitate closure. During early pregnancy and delayed implantation, when the first stage of closure is observed in the rat and mouse, uterine epithelial cells display intense endocytotic activity (Enders \& Nelson, 1973; Parr \& Parr, 1974, 1977). The cells take up intraluminal markers such as ferritin and horseradish peroxidase not only into small coated vesicles $(0.1 \mu \mathrm{m})$ but into large endocytotic vacuoles $(3.0 \mu \mathrm{m})$ formed from cup-like protrusions or pinopods (Enders \& Nelson, 1973) which develop from the apical surfaces.

Endocytosis of intraluminal tracers has also been studied in ovariectomized rats treated with ovarian hormones in various regimens (Leroy, Van Hoeck \& Bogaert, 1976). Uterine closure was not investigated in these animals but it was reported that endocytosis occurred in untreated ovariectomized rats in which closure is known not to occur. If uterine closure is mediated by endocytosis, we would expect to find the simultaneous appearance of both events under the same physiological conditions. Accordingly, in the present investigation, we have studied the effects of ovarian hormones on epithelial cell endocytosis and uterine closure in the same animals.

\footnotetext{
* Present address: Southern Illinois University, School of Medicine, Anatomy Department, Carbondale, Illinois 62901, U.S.A.
} 


\section{Materials and Methods}

Forty-six virgin albino female rats weighing 200-250 g were obtained from the Flinders University Central Animal House or the Southern Illinois University Vivarium. The animals were carefully ovariectomized bilaterally, allowed to recover for 3-6 weeks, and then treated with ovarian hormones in a variety of combinations (see Table 1). Approximately $25-30 \mathrm{~h}$ after the last hormonal injection, the rats were anaesthetized with tribromoethanol and one uterine horn was injected with $50 \mu \mathrm{l}$ of a $5 \%$ solution of purified ferritin (Sigma Chemical Co., St Louis, Missouri) in medium 199 (Parr \& Oei, 1973). After $1 \mathrm{~h}$ the uteri were either fixed by vascular perfusion with a mixture of $2.5 \%$ glutaraldehyde and $2 \%$ paraformaldehyde in $0.1 \mathrm{M}$-cacodylate buffer, $\mathrm{pH} 7 \cdot 4$, at room temperature or they were removed and fixed by immersion in the same fixative. For the demonstration of endocytosis, tissues from the ferritin-injected horns were dehydrated, embedded in paraffin wax, and sections $(5 \mu \mathrm{m})$ were stained with Perls' Prussian Blue reaction mixture for iron. For the demonstration of closure, uterine segments from the contralateral horns were washed in cacodylate buffer $(0.1 \mathrm{M}, \mathrm{pH} 7 \cdot 4)$ overnight $\left(4^{\circ} \mathrm{C}\right)$, post-fixed in $1 \%$ osmium tetroxide for $1 \mathrm{~h}$ $\left(4^{\circ} \mathrm{C}\right)$, washed and dehydrated. Some of the tissue segments were embedded in Spurr's medium and semithin sections were stained with toluidine blue in borate buffer for light microscopy. Other segments were cut open to expose the luminal surfaces and processed for scanning electron microscopy. The tissues were dried by the critical-point method, mounted on stubs, gold coated, and examined with an ETEC autoscan scanning microscope. Variations in the compression of the tissues and the section thickness prevented scoring of cells for endocytotic activity and Perls' staining.

\section{Results}

Uterine luminal epithelial cells from ovariectomized rats treated with progesterone alone or oestrogen and progesterone exhibited endocytotic activity. The cells took up intraluminal ferritin as demonstrated by the presence of Perls'-stained lysosomes in the cytoplasm (Table 1; Pl. 1, Fig. 2)

\section{PLATE 1}

Fig. 1. Light micrograph of the rat uterine epithelium from an ovariectomized rat $1 \mathrm{~h}$ after an intraluminal injection of $50 \mu \mathrm{l}$ ferritin solution and stained histochemically for iron. The cells do not show any Perls' staining. $\times 842$.

Fig. 2. Light micrograph of the rat uterine epithelium from an ovariectomized rat treated with oestradiol- $17 \beta$ and progesterone $1 \mathrm{~h}$ after an intraluminal injection of ferritin and stained histochemically for iron. Ferritin was incorporated into the cells and accumulated in lysosomes which appear as dark granules with Perls' stain (arrows). $\times 842$.

Fig. 3. A scanning electron micrograph of the luminal surface of the uterus of an ovariectomized rat. The apical surfaces of the epithelial cells are covered by numerous short microvilli while somewhat longer microvilli are localized at the periphery of the cells forming distinct cell borders. $\times 1460$.

Fig. 4. A scanning electron micrograph of the luminal surface of the uterus of an ovariectomized rat treated with oestradiol- $17 \beta$ and progesterone. Some pinopods (arrow) are seen projecting into the lumen from the apical surface of the epithelial cells. $\times 1540$.

Fig. 5. A light micrograph of an ovariectomized rat uterus treated with oestradiol- $17 \beta$ and progesterone. The uterus was fixed by vascular perfusion with $2.5 \%$ glutaraldehyde and $2 \%$ paraformaldehyde. Note the closed lumen. $\times 25$.

Fig. 6. A light micrograph of the uterus of an ovariectomized rat treated with oestradiol-17 $\beta$ and progesterone but fixed by immersion in the same fixative as the uterus in Fig. 5 . Note the open lumen. $\times 25$. 
PLATF
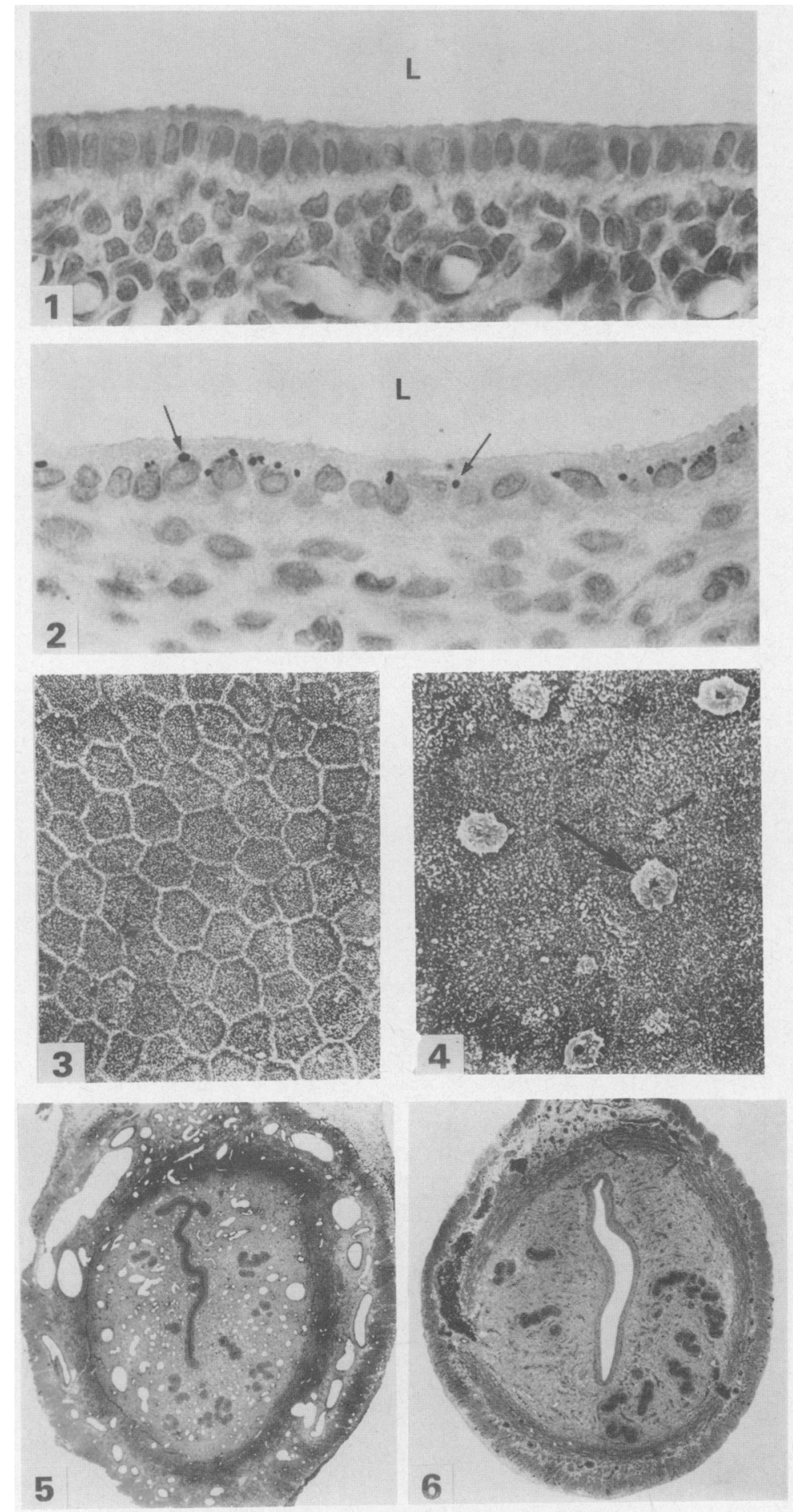
and pinopods projecting from the apical parts of the cells (Pl. 1, Fig. 4). The first stage of uterine closure also occurred in these animals (Table 1; Pl. 1, Fig. 5). There was no endocytotic activity in uterine epithelial cells of untreated ovariectomized rats (PI. 1, Figs 1 \& 3) or rats treated with oestrogen alone (Table 1), nor did uterine closure occur in these animals. The first stage of closure could only be demonstrated in uteri fixed by vascular perfusion. The uterine lumen was open in all hormone-treated or untreated rats when the uteri were fixed by immersion (Table 1; Pl. 1, Fig. 6).

Table 1. The effects of ovarian hormones on endocytosis in the uterine epithelial cells and on uterine closure in ovariectomized rats

\begin{tabular}{|c|c|c|c|c|c|c|c|c|c|c|c|c|}
\hline \multicolumn{9}{|c|}{ Hormone treatment (days) ${ }^{*}$} & \multirow{2}{*}{$\begin{array}{l}\text { Perls' staining } \\
\text { (no. of rats) }\end{array}$} & \multirow{2}{*}{$\begin{array}{l}\text { Pinopods } \\
\text { (no. of rats) }\end{array}$} & \multicolumn{2}{|c|}{ Uterine lumen (no. of rats) } \\
\hline 1 & 2 & 3 & 4 & 5 & 6 & 7 & 8 & 9 & & & Perfusion fixation & Immersion fixation \\
\hline- & - & - & - & - & - & - & - & $\mathbf{K}$ & $-(10)$ & $-(5)$ & Open (4) & Open (6) \\
\hline $\mathrm{E}$ & E & $\mathrm{K}$ & - & - & - & - & - & - & $-(10)$ & $-(3)$ & Open (5) & Open (5) \\
\hline- & - & - & - & - & $\mathrm{P}$ & $\mathrm{P}$ & $\mathbf{P}$ & $\mathbf{K}$ & $+(10)$ & $+(4)$ & Closed (8) & Open (5) \\
\hline E & E & - & - & - & $\mathbf{P}$ & $\mathbf{P}$ & $\mathrm{P}$ & $\mathbf{K}$ & $+(10)$ & $+(10)$ & Closed (7) & Open (6) \\
\hline
\end{tabular}

* Day 1 is $3-6$ weeks after ovariectomy; $E=500 \mathrm{ng}$ oestradiol-17 $\beta, \mathrm{P}=5 \mathrm{mg}$ progesterone. All rats were killed (K) $25-30 \mathrm{~h}$ after the final hormone injection.

\section{Discussion}

In the rat both uterine closure and epithelial cell endocytosis appear in response to progesterone or progesterone after oestrogen priming but not to oestrogen alone or in hormonally untreated animals. There is therefore a close correspondence between the timing of the two physiological events in these experimental situations and during normal pregnancy and delayed implantation. However, Leroy et al. (1976), in studies of ovariectomized rats treated with ovarian hormones, reported that uterine epithelial cells displayed endocytotic activity not only after progesterone treatment but also in untreated ovariectomized rats. The epithelial cells of ovariectomized rats showed uptake of intraluminal ferritin but not trypan blue. In this study the epithelial cells from hormonally untreated ovariectomized rats did not show any uptake of intraluminally administered ferritin as determined by Perls' staining, nor did they show any pinopods by scanning electron microscopy. Transmission electron microscopic studies of similar cells failed to show organelles that would be expected to occur in cells actively undergoing endocytosis, such as endocytotic vacuoles and numerous lysosomes (Parr, 1982). In contrast, ovariectomized rats treated with progesterone alone or with progesterone after oestrogen priming showed abundant ferritin uptake, many pinopods, and endocytotic vacuoles and numerous lysosomes (Parr, 1982). I conclude that the endocytotic activity is negligible in the uterine epithelium of ovariectomized rats, but that such activity is greatly increased by progesterone treatment, to levels that appear to be comparable with those observed in normal pregnancy and delayed implantation under similar assay conditions (Parr \& Parr, 1978; M. B. Parr, unpublished observation). The assay conditions used by Leroy et al. (1976) involved a much longer exposure to the ferritin tracer and may have a different physiological significance. My observations and conclusions support the proposal that endocytosis of luminal fluids by the uterine epithelium during the preimplantation period may facilitate uterine closure (Mayer et al., 1967; Enders \& Nelson, 1973), but a causal relationship between these two physiological processes remains to be shown.

Demonstration of the apposition of uterine epithelia during the first stage of closure in the rat not only depends on the hormonal treatment but on the method of uterine fixation. All uteri from rats treated with progesterone or oestradiol plus progesterone showed closure when they were fixed by vascular perfusion, whereas all uteri fixed by immersion in the same fixative had open lumina. 
In addition, touching the uterus in situ before perfusion fixation frequently resulted in a uterus with an open lumen. It seems possible that under these conditions and during fixation by immersion the myometrium may contract, pulling apart the apposed epithelial layers, and that this artefact does not occur in uteri fixed in situ. Similar types of fixation artefacts were also reported by Martin $e t$ al. (1970) and Ljungkvist \& Nilsson (1974) and emphasize the importance of fixation methods in the preparation of uterine tissues to demonstrate uterine closure.

Special thanks to Sue Williams and Nancy Kammlade for technical assistance.

\section{References}

Enders, A.C. \& Nelson, M.D. (1973) Pinocytotic activity of the uterus of the rat. Am. J. Anat. 138, 277-300.

Enders, A.C. \& Schlarke, S. (1969) Cytological aspects of trophoblast-uterine interaction in early implantation. Am. J. Anat. 125, 1-30.

Finn, C.A. (1975) The endometrium. In The Uterus, pp. 17-104. Eds C. A. Finn \& D. G. Porter. ELEK Science, London.

Hedlund, K. \& Nilsson, O. (1971) Hormonal requirements for uterine attachment reaction and blastocyst implantation in the mouse, hamster and guinea pig. J. Reprod. Fert. 26, 267-269.

Leroy, F., Van Hoeck \& Bogaert, C. (1976) Hormonal control of pinocytosis in the uterine epithelium of the rat. J. Reprod. Fert. 47, 59-62.

Ljungkvist, I. \& Nilsson, O. (1974) Blastocyst-endometrial contact and pontamine blue reaction during normal implantation in the rat. $J$. Endocr. 60, 149154.

Martin, L., Finn, C.A. \& Carter, J. (1970) Effects of progesterone and oestradiol-17 $\beta$ on the luminal epithelium of the mouse uterus. J. Reprod. Fert. 21, 461-469.
Mayer, G., Nilsson, O. \& Reinius, S. (1967) Cell membrane changes of uterine epithelium and trophoblast during blastocyst attachment in the rat. $Z$. Anat. EntwGesch. 126, 43-48.

Parr, E.L. \& Oei, J.S. (1973) Immobilization of membrane $\mathrm{H}-2$ antigens by paraformaldehyde fixation. J. Cell Biol. 59, 537-542.

Parr, M. (1982) Apical vesicles in the rat uterine epithelium during early pregnancy: a morphometric study. Biol. Reprod. 26, 915-924.

Parr, M.B. \& Parr, E.L. (1974) Uterine luminal epithelium: protrusions mediate endocytosis, not apocrine secretion, in the rat. Biol. Reprod. 11, 220233.

Parr, M.B. \& Parr, E.L. (1977) Endocytosis in the uterine epithelium of the mouse. J. Reprod. Fert. 50, 151-153.

Parr, M.B. \& Parr, E.L. (1978) Uptake and fate of ferritin in the uterine epithelium of the rat during early pregnancy. J. Reprod. Fert. 52, 183-188.

Received 15 September 1982 